\title{
Comparable Electrode Impedance and Speech Perception at 12 Months after Cochlear Implantation Using Round Window versus Cochleostomy: An Analysis of 40 Patients
}

\author{
Xiaoting Cheng ${ }^{a, b}$ Bing Wang ${ }^{a, b}$ Yangwenyi Liu ${ }^{a, b} \quad$ Yasheng Yuan ${ }^{a, b}$ \\ Yilai Shu ${ }^{a, b}$ Bing Chen ${ }^{a, b}$ \\ aDepartment of Otolaryngology, Head and Neck Surgery, Eye and Ear, Nose, Throat \\ Hospital of Fudan University, Shanghai, China; ${ }^{b} \mathrm{NHC}$ Key Laboratory of Hearing Medicine, \\ Fudan University, Shanghai, China
}

\section{Keywords}

Cochlear implantation $\cdot$ Impedance $\cdot$ Speech perception $\cdot$ Round window $\cdot$ Cochleostomy

\begin{abstract}
Objective: The objective of this study was to examine whether cochlear implantation using the round window (RW) route versus cochleostomy achieves comparable electrode impedance and hearing results. Methods: This retrospective analysis included 40 patients receiving a cochlear implant (REZ-1): 20 using the RW approach and the remaining 20 using cochleostomy. Electrode impedance and tone, vowel, consonant, disyllable and sentence perception were measured during and after the implantation. Results: Electrode impedance did not differ significantly between the 2 groups at any time points $[F(1,38)=1.84 ; p=0.184]$ : $1.87,5.16$, 6.47 and $6.70 \mathrm{k} \Omega$ in the RW group versus $2.86,5.33,6.92$ and $8.16 \mathrm{k} \Omega$ in the cochleostomy group at $0,1,3$ and 12 months, respectively. There was no significant difference between the RW and cochleostomy groups for tone ( 77.50 vs. $80.50 \% ; p=0.472)$, vowel $(77.70$ vs. $78.65 \%$; $p=0.760)$, consonant ( 75.50 vs. $78.25 \% ; p=0.443)$, disyllable $(78.60$ vs. $81.50 \% ; p=0.317)$ and sentence ( 50.90 vs. $52.50 \% ; p=0.684$ ) perception at 12 months. Conclusion: The RW approach is comparable to cochleostomy in electrode placement as reflected by impedance and function as reflected by tone, vowel, consonant, disyllable and sentence perception.
\end{abstract}

Xiaoting Cheng and Bing Wang contributed equally to this work.

Bing Chen

Department of Otolaryngology, Head and Neck Surgery

Eye and Ear, Nose, Throat Hospital of Fudan University

83 Fen Yang Road, Shanghai, 200031 (China)

E-Mail bingchen@fudan.edu.cn or
Yilai Shu

NHC Key Laboratory of Hearing Medicine, Fudan University 83 Fen Yang Road, Shanghai, 200031 (China)

E-Mail yilai_shu@fudan.edu.cn 
Cheng et al.: Impedance and Speech after Cochlear Implantation Using Round Window versus Cochleostomy

\section{Introduction}

Cochlear implantation (CI) has been increasingly used to treat sensorineural deafness. The implant converts the sound signal into electrical stimulation and then stimulates auditory nerve fibers to produce hearing $[1,2]$. A number of factors, including the causes of deafness, age at implantation, coding strategy, deafness duration and the degree of inner ear malformation, influence patient outcomes [3-8]. However, there still is a need to investigate the influence of other factors on $\mathrm{CI}$ outcomes because the above factors cannot account for all variances in $\mathrm{CI}$ performance.

The round window (RW) route and cochleostomy are the two major approaches for implant insertion [9]. Cochleostomy is an alternative access route to the RW approach. Cochleostomy provides a larger area for electrode insertion and does not require the hook region of the basal turn. However, as the design of the electrode array has developed, and with the advent of hearing preservation, the RW zone is considered as a less traumatic site for electrode insertion $[10,11]$.

Previous studies that compared the RW and cochleostomy approaches have yielded conflicting results. Gu et al. [12] showed that the RW approach achieved lower impedance than the cochleostomy approach, whereas Hamada et al. [13] held different viewpoints that the RW and cochleostomy approaches provided comparable impacts on electrode impedance. Except for electrode impedance, residual hearing, insertion depth and speech perception were compared between the 2 approaches. The majority of results showed that the 2 approaches provided comparable results for preserving the residual hearing, insertion depth and speech perception [14-18]. Rowe et al. [19] showed that the RW approach induced delayed low-frequency hearing loss which may be due to the muscle graft used to seal the RW incision. Hod et al. [18] showed a similar degree of hearing loss between the RW and cochleostomy approaches in an animal model 1 week after surgery. Above all, few studies have a comprehensive evaluation to indicate the impact of these 2 surgical approaches for CI users using the same type of electrode.

During and after implantation, various parameters can be used to evaluate the integrity and function of the cochlear device, in which electrode impedance and speech perception are the most common measurement parameters. Electrode impedance reflects the status of the tissue-to-electrode interface and surrounding environment of the cochlea [20,21] and is highly indicative of the integrity and function of electrodes. Thus, it is applied to monitor the function of the cochlear implant and debug it clinically. Speech perception, which is regarded as an important subjective measurement, can be used to indicate the functional outcomes of the cochlear implant [22-24]. By far, there was no comprehensive evaluation including electrode impedance and speech perception for CI users using the same type of device to compare the effect between cochleostomy and RW approaches.

The aim of this study was to explore whether the 2 previously described different surgical access routes will lead to different impedance and functional outcomes. In the present study, we compared electrode impedance and speech perception in 2 groups of patients receiving CI using RW versus cochleostomy approaches.

\section{Materials and Methods}

Statement of Ethics

This study was approved by the Ethics Committee of Eye and Ear, Nose, Throat Hospital of Fudan University, Shanghai, China. 
Cheng et al.: Impedance and Speech after Cochlear Implantation Using Round Window versus Cochleostomy

Table 1. Demographic information for the RW and cochleostomy groups

\begin{tabular}{lccc}
\hline & $\begin{array}{l}\text { RW } \\
(n=20)\end{array}$ & $\begin{array}{l}\text { Cochleostomy } \\
(n=20)\end{array}$ & $\begin{array}{l}p \\
(p>0.05)\end{array}$ \\
\hline Gender (male:female) & $12: 8$ & $13: 7$ & 0.744 \\
Operation ear (left:right) & $7: 13$ & $6: 14$ & 0.736 \\
Age at implantation (mean \pm SD), years & $40.5 \pm 18.0$ & $37.7 \pm 11.6$ & 0.563 \\
Deafness duration (mean \pm SD), years & $13.4 \pm 11.1$ & $12.6 \pm 9.0$ & 0.792 \\
\hline
\end{tabular}

RW, round window; SD, standard deviation.

Table 2. Etiology of deafness $(n)$

\begin{tabular}{lll}
\hline & $\begin{array}{l}\text { Cochleostomy } \\
(n=20)\end{array}$ & $\begin{array}{l}\text { RW } \\
(n=20)\end{array}$ \\
\hline Unknown & 12 & 9 \\
Meningitis & 2 & 2 \\
Enlarged vestibular aqueduct & 1 & 1 \\
Drug-induced deafness & 4 & 6 \\
Sudden deafness & 1 & 1 \\
Noised-induced deafness & 0 & 1 \\
\hline
\end{tabular}

RW, round window.

Participants

This study included 40 participants with postlinguistic severe-to-profound sensorineural hearing loss who received a cochlear implant between February 2012 and March 2016 in the Eye and Ear, Nose, Throat Hospital of Fudan University. They were classified into 2 groups according to surgical approach: one group $(n=20)$ underwent CI via the RW approach, and the other group $(n=20)$ underwent surgery via the cochleostomy. All participants received the same type of cochlear device (REZ-1, Listent, Shanghai, China), and they all received full electrode insertion and had the same speech process system. Table 1 gives detailed demographic information for the RW and cochleostomy groups, including sex, age at implantation, operation ear and deafness duration. The etiologies of deafness in the 2 groups are summarized in Table 2.

\section{Surgical Techniques}

The transmastoid facial recess approach to the scala tympani and RW was used in both approaches. Mastoidectomy was performed first, followed by tympanotomy [19, 25].

The RW niche was identified and removed using a drill, after which the RW membrane was exposed. A microsurgical needle or knife was used to incise the RW membrane and the electrode was then slowly and steadily inserted. Cochleostomy was made at the zone anterior-inferior to the RW using a drill. The electrode was inserted slowly and steadily to avoid a rapid change in the cochlear fluids, and the electrode was appropriately oriented to the modiolus. Following insertion, muscle or fascia was used to seal the cochleostomy.

\section{Cochlear Implant}

The cochlear implant was from Listent (REZ-1; Shanghai, China) and is equipped with a contour electrode (27 mm in length, Fig. 1). The device was approved by the China Food and Drug Administration (3460261).

\section{Impedance Measurements}

Impedance was measured using a software MAP (Listent) under the default setting (66-uspulse width, 2,500 pps rate and MTone strategy) in the BP +1 mode. At each time point, testing was conducted for at least 3 times, in order to acquire an average. Electrodes 1-7 represent the apical turn; 8-14 represent the middle turn; 15-22 represent the basal turn. 
Cheng et al.: Impedance and Speech after Cochlear Implantation Using Round Window versus Cochleostomy

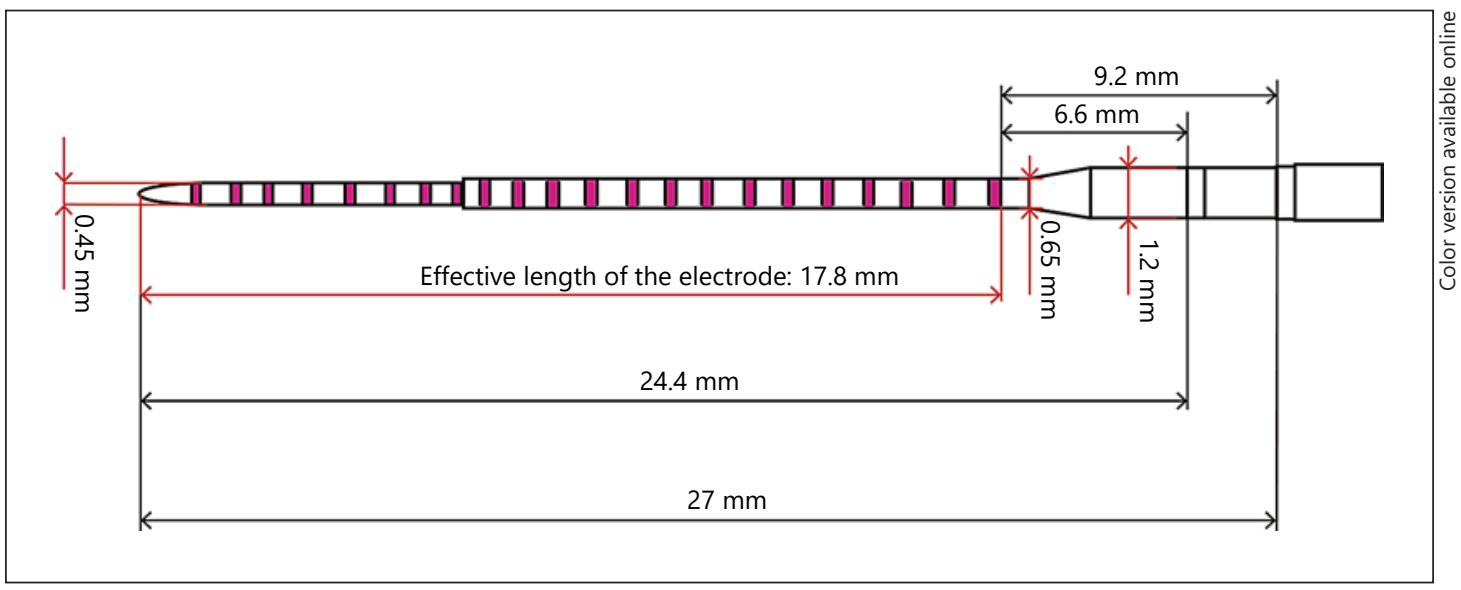

Fig. 1. A schematic diagram of the REZ-1 electrode array.

\section{Speech Perception}

Stimuli were presented in sound field at $65 \mathrm{~dB}$ SPL via a single loudspeaker positioned $1 \mathrm{~m}$ away from the subject, who directly faced the speaker. The speech perception of those patients was measured by using tone, vowel, consonant, disyllable and sentence identification [26]. Each test was conducted for each subject twice, and performance was averaged across test runs.

Mandarin Tone Recognition in Quiet

Mandarin tone identification consisted of monosyllable and disyllable tonal perception which have 4 tonal patterns. The four tonal patterns included tone 1 (high-level), tone 2 (high-rising), tone 3 (fallingrising) and tone 4 (high-falling). The monosyllable tonal perception consisted of 5 monosyllables (i, $u$, ma, bo, yu), and the disyllables consisted of the following 23 monosyllables (yi, shu, fei, wan, qi, wa, pai, jiao, he, xiang, yu, fang, xi, tang, cao, mu, pao, bei, deng, ya, guo, bi, mao). For monosyllable tonal perception, a stimulus would be randomly selected from the stimulus set and presented to the subject, who responded by pointing out 1 of the 4 pictures (a monosyllable with 4 tones). For disyllable tonal perception, a stimulus would be randomly selected from the stimulus set and presented to the subject, who responded by pointing out 1 of the 2 pictures ( 2 disyllables created by a monosyllable with 2 tones such as yī fu and yǐ zi). No trial-by-trial feedback or training was provided.

Vowel Recognition in Quiet

There were 31 vowel stimuli in the stimulus set and the vowel stimuli consisted of 25 groups of 3 vowels each; the initial consonant for each group was the same. The 25 groups of vowel stimuli included: (1) bí, bái, bá, (2) fēng, fāng, fēi, (3) mō, mā, māo, (4) dù, dì, dòu, (5) tīng, tuō, tī, (6) nǎi, nứ, niăo, (7) luó, lóu, lín, (8) lán, Iíng, lí, (9) guā, gāo, guō, (10) yā, ȳ̄, yān, (11) hēi, huā, hē, (12) chē, chī, chuāng, (13) xié, xǐ, xióng, (14) shān, shuǐ, shǔ, (15) qún, qiáng, qiú, (16) xiā, xuē, xīng, (17) lù, liàn, là, (18) zǒu, zăo, zuǐ, (19) yá, yú, yuan, (20) hú, hé, hóng, (21) dēng, dāo, dūn, (22) běn, bǐ, biăo, (23) xiàng, xiàn, xiào, (24) jī, jiā, jìng, and (25) cài, cì, cuò. Thus, during testing, a group would be randomly selected and a vowel stimulus would be randomly selected from within the group and presented to the subject, who responded by clicking on 1 of the 3 pictures labeled according to the vowels in the selected group. No trial-by-trial feedback or training was provided.

Consonant Recognition in Quiet

There were 21 consonant stimuli in the stimulus set and the consonant stimuli consisted of 25 groups of 3 consonants each; the final vowel for each group was the same. The 25 groups of consonant stimuli included: (1) bái, chái, mái, (2) tă, dǎ, mă, (3) bāo, dāo, māo, (4) hē, gē, chē, (5) tuō, guō, zhuō, (6) qiē, tiē, jiēe, (7) guā, shuā, huā, (8) niǎo, jiăo, biăo, (9) dēng, fēng, rēng, (10) pān, bān, shān, (11) chòu, lóu, hóu, (12) cì, sì, rì, (13) xiàn, miàn, liàn, (14) lóng, hóng, chóng, (15) wò, zuò, luò, (16) liù, qiú, niú, (17) jī, qī, xī, (18) kū, zhū, shū, (19) pén, mén, wén, (20) líng, xīng, jìng, (21) shuǐ, zuǐ, tuǐ, (22) gǒu, shǒu, zǒu, (23) mèi, hēi, fēi, (24) yú, lú, nŭ́, and (25) jiā, xiā, yā. Thus, during testing, a group would be randomly selected and a consonant stimulus 
Cheng et al.: Impedance and Speech after Cochlear Implantation Using Round Window versus Cochleostomy

would be randomly selected from within the group and presented to the subject, who responded by clicking on 1 of the 3 pictures labeled according to the consonants in the selected group. No trial-by-trial feedback or training was provided.

Disyllable Recognition in Quiet

Disyllable stimuli consisted of 12 groups of 5 disyllables each. The 12 groups of disyllable stimuli included: (1) fēi jī, qì qiú, ping guǒ, gōng jī, diàn dēng, (2) guān mén, bīng gāo, mén chuāng, wū yā, pāi qiú, (3) xióng māo, nŭ hái, yá shuā, shù yè, xǐ zăo, (4) chī fàn, mō xiàng, kū nào, chàng gē, shuì jiào, (5) hóng zhǐ, săo dì, yóu xì, jiāo huā, liăn pén, (6) huǒ chē, lù̀ căo, hē shuǐ, biān pào, tán qín, (7) yī fū, tiào shéng, tài yáng, nŭ rén, yuè liàng, (8) wán jü, xióng māo, shǒu juàn, bái cài, kàn shū, (9) mă chē, hú dié, bīng gāo, zhěn tóu, jī mù, (10) xīguā, diàn shì, săo dì, mì fēng, luó bō, (11) yī shēng, chóng zī, zǒu lù, máo jīn, tóu fa, and (12) xǐ shǒu, pǎo bù, shuǐ bēi, yá shuā, qǐchuáng. Thus, there were 24 disyllable stimuli in the stimulus set. During testing, a group would be randomly selected and a disyllable stimulus would be randomly selected from within the group and presented to the subject, who responded by clicking on 1 of the 5 pictures labeled according to the disyllables in the selected group. No trial-by-trial feedback or training was provided.

Sentence Recognition in Quiet

Sentence recognition consisted of 4 groups of 5 sentences, each stimulus set included 50 key words. During testing, a list was randomly selected and a sentence was randomly selected from the list and presented to the subject, who repeated as many words as possible. The experimenter scored the correct key words.

Data Analysis

IBM SPSS Statistics version 20 (IBM Corp., USA) was used to analyze the data. The $\chi^{2}$ test, post hoc Bonferroni pairwise comparisons and a repeated-measures analysis of variance (ANOVA) were used. The results are expressed as mean and standard deviations, and the level of statistical significance was set at a value of $p<0.05$.

\section{Results}

\section{Electrode Impedance}

The demographic data of 40 participants are shown in Table 1. No significant differences between the RW and cochleostomy groups in terms of gender, implantation ear, deafness duration and age at implantation were observed. Figure 2a shows mean impedances of those 2 groups at different test points. For the RW group $(n=20)$, the mean impedance was 1.87 $(\mathrm{SD}=0.67), 5.16(\mathrm{SD}=0.82), 6.47(\mathrm{SD}=2.17)$ and $6.70 \mathrm{k} \Omega(\mathrm{SD}=2.62)$ for $0,1,3$ and 12 months after implantation, respectively. For the cochleostomy group $(n=20)$, the mean impedance was $2.86(\mathrm{SD}=2.10), 5.33(\mathrm{SD}=1.77), 6.92(\mathrm{SD}=2.99)$ and $8.16 \mathrm{k} \Omega(\mathrm{SD}=3.59)$ for $0,1,3$ and 12 months after implantation, respectively. A repeated-measures ANOVA was performed on the data shown in Figure 2, with test time points as the within-subject factor and group as the between-subject factor. Results showed a significant effect for test time points $[F(3,114)=$ 42.72; $p=0.000]$, but not for group $[F(1,38)=1.84 ; p=0.184]$; meanwhile, there was no significant interaction $[F(3,114)=0.60 ; p=0.515]$. Post hoc Bonferroni pairwise comparisons showed that there was no significant difference between the 2 groups for $0(p=0.056)$, $1(p=0.708), 3(p=0.586)$ and $12(p=0.300)$ months after implantation.

Figure $2 \mathrm{~b}-\mathrm{d}$ shows the impedances of apical, middle and basal turns for the 2 surgical approaches at the different time points. For the RW group, a repeated-measures ANOVA was performed, with test time points as the within-subject factor and different turns as the between-subject factor. Results showed a significant effect for test time points $[F(3,171)=$ 106.96; $p=0.000]$, different turns $[F(2,57)=3.38 ; p=0.041]$ and interaction $[F(6,171)=$ 4.84; $p=0.006]$. Bonferroni tests showed that the mean impedance of the basal turn was higher than that of the apical turn $(p=0.017)$. For the cochleostomy group, results showed a 

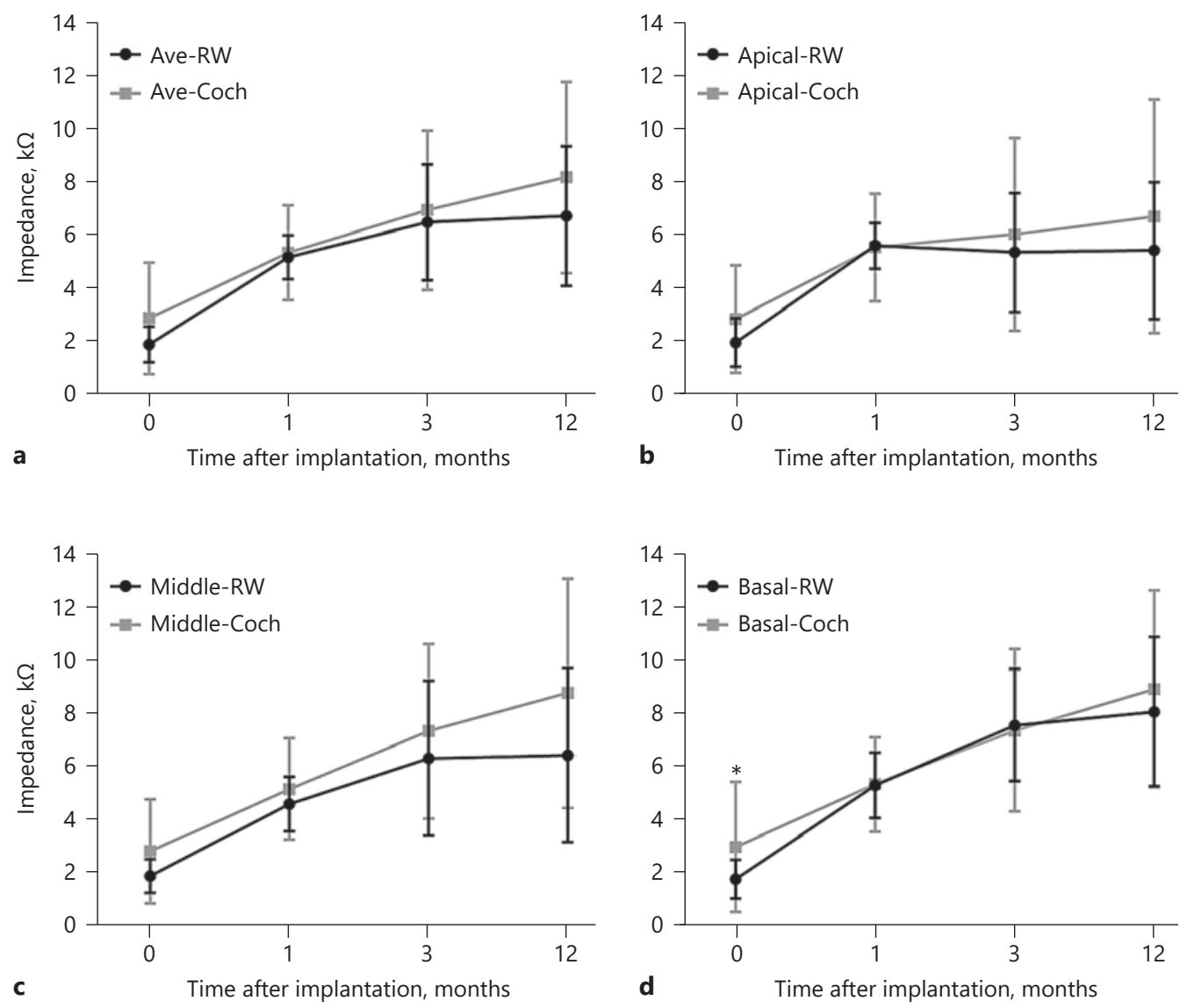

Fig. 2. Intra- and postoperative impedances at different test points of different turns for RW and cochleostomy groups. The error bars represent the standard deviation. The asterisk indicates statistical significance between 2 groups at a certain time point. RW, round window; Coch, cochleostomy; Ave, average; apical, apical turn; middle, middle turn; basal, basal turn.

significant effect for test time points $[F(3,171)=58.89 ; p=0.000]$, but not for different turns $[F(2,57)=0.87 ; p=0.425]$ and interaction $[F(6,171)=1.63 ; p=0.175]$.

For the apical turn, results showed a significant effect for test time points $[F(3,114)=$ $28.50 ; p=0.000]$, but not for group $[F(1,38)=1.31 ; p=0.259]$ and interaction $[F(3,114)=$ $0.79 ; p=0.438]$. Post hoc Bonferroni pairwise comparisons showed that there was no significant difference between the 2 groups for $0(p=0.088), 1(p=0.904), 3(p=0.479)$ and 12 $(p=0.265)$ months after implantation.

For the middle turn, results showed a significant effect for test time points $[F(3,114)=$ 51.31; $p=0.000]$, but not for group $[F(1,38)=3.68 ; p=0.063]$ and interaction $[F(3,114)=$ $1.41 ; p=0.252]$. Post hoc Bonferroni pairwise comparisons showed that there was no significant difference between the 2 groups for $0(p=0.055), 1(p=0.259), 3(p=0.304)$ and 12 ( $p=0.062$ ) months after implantation.

For the basal turn, results showed a significant effect for test time points $[F(3,114)=$ 81.58; $p=0.000]$, but not for group $[F(1,38)=0.722 ; p=0.401]$ and interaction $[F(3,114)=$ 1.23; $p=0.296]$. Post hoc Bonferroni pairwise comparisons showed that there was a significant difference between the 2 groups at the 0 -month time point $(p=0.046)$. No significant 
Cheng et al.: Impedance and Speech after Cochlear Implantation Using Round Window versus Cochleostomy



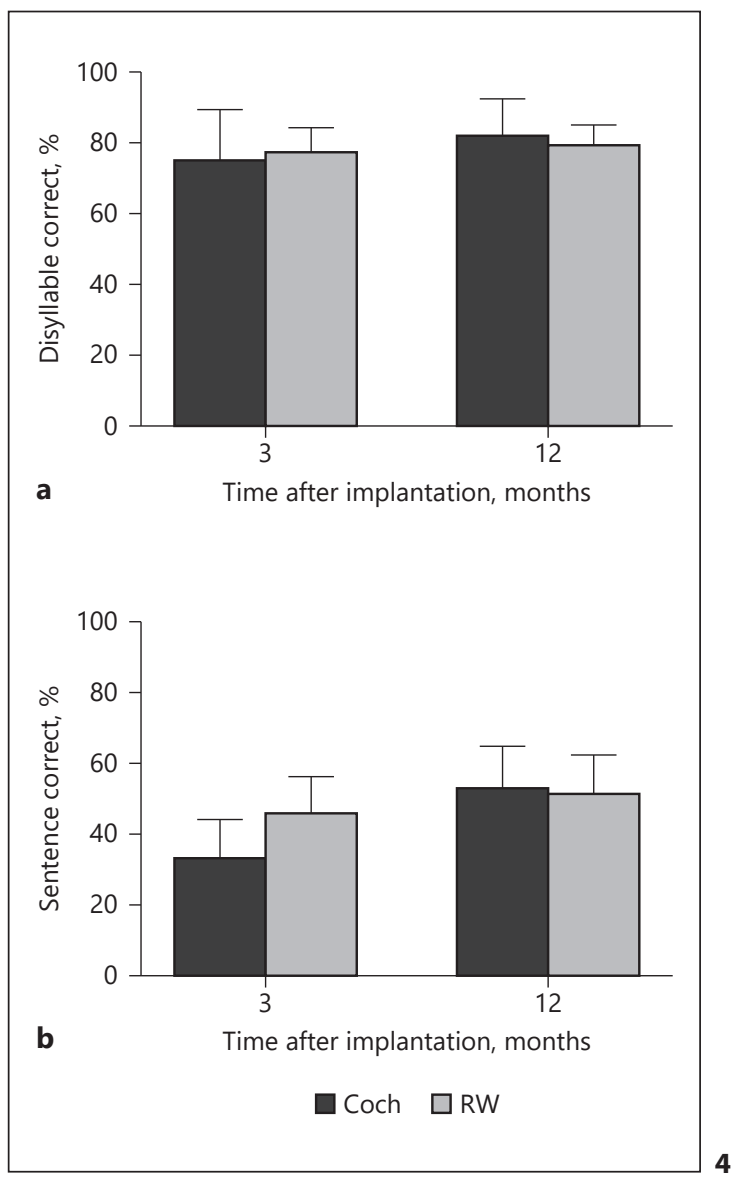

Fig. 3. Tone, vowel and consonant perception of RW and cochleostomy groups 3 and 12 months after implantation. RW, round window; Coch, cochleostomy. The error bars represent the standard deviation.

Fig. 4. Disyllable and sentence perception of RW and cochleostomy groups 3 and 12 months after implantation. RW, round window; Coch, cochleostomy. The error bars represent the standard deviation.

difference between the 2 groups for $1(p=0.935), 3(p=0.816)$ and $12(p=0.418)$ months after implantation was observed.

\section{Speech Perception}

Figures 3 and 4 show the tone, vowel and consonant, disyllable and sentence perception of the RW and cochleostomy group 3 and 12 months after implantation. For the RW group, mean tone, vowel and consonant, disyllable and sentence perception were $73.50 \%$ (SD = 15.3), 73.00\% ( $\mathrm{SD}=8.2$ ), $72.60 \%(\mathrm{SD}=8.6), 76.80 \%(\mathrm{SD}=7.5), 45.1 \%(\mathrm{SD}=11.2)$ and $77.50 \%$ $(\mathrm{SD}=11.2), 77.70 \%(\mathrm{SD}=6.7), 75.50 \%(\mathrm{SD}=9.3), 78.60 \%(\mathrm{SD}=6.5)$ and $50.90 \%(\mathrm{SD}=11.4)$ 
Cheng et al.: Impedance and Speech after Cochlear Implantation Using Round Window versus Cochleostomy

for 3 and 12 months after implantation, respectively. For the cochleostomy group, mean tone, vowel and consonant, disyllable and sentence perception were $75.00 \%$ (SD $=14.7), 71.40 \%$ $(\mathrm{SD}=15.4), 72.65 \%(\mathrm{SD}=13.8), 74.40 \%(\mathrm{SD}=15.1), 32.45 \%(\mathrm{SD}=11.7)$ and $80.50 \%(\mathrm{SD}=$ 14.7), 78.65\% (SD = 12.1), 78.25\% (SD = 12.9), 81.50\% (SD = 11.0) and 52.5\% (SD = 12.4) for 3 and 12 months after implantation, respectively. Arepeated-measures ANOVA was performed on the data shown in Figures 3 and 4, with test time points as the within-subject factor and group as the between-subject factor.

For tone perception, results showed no significant effect for test time points $[F(1,38)=$ $3.40 ; p=0.081]$, group $[F(1,38)=0.51 ; p=0.484]$ and interaction $[F(1,38)=0.090 ; p=0.767]$. Post hoc Bonferroni pairwise comparisons showed that there was no significant difference between the 2 groups for 3 ( $p=0.754)$ and $12(p=0.472)$ months after implantation.

For vowel perception, results showed a significant effect for test time points $[F(1,38)=$ $14.79 ; p=0.001]$, but not for group $[F(1,38)=0.016 ; p=0.901]$ and interaction $[F(1,38)=$ $0.486 ; p=0.494]$. Post hoc Bonferroni pairwise comparisons showed that there was no significant difference between the 2 groups for $3(p=0.685)$ and $12(p=0.760)$ months after implantation.

For consonant perception, results showed a significant effect for test time points $[F(1,38)=4.92 ; p=0.039]$, but not for group $[F(1,38)=0.424 ; p=0.523]$ and interaction $[F(1,38)=0.550 ; p=0.467]$. Post hoc Bonferroni pairwise comparisons showed that there was no significant difference between the 2 groups for $3(p=0.989)$ and $12(p=0.443)$ months after implantation.

For disyllable perception, results showed a significant effect for test time points $[F(1,38)=8.95 ; p=0.008]$, but not for group $[F(1,38)=0.009 ; p=0.924]$ and interaction $[F(1,38)=2.69 ; p=0.118]$. Post hoc Bonferroni pairwise comparisons showed that there was no significant difference between the 2 groups for $3(p=0.530)$ and $12(p=0.317)$ months after implantation.

For sentence perception, results showed a significant effect for test time points $[F(1,38)=69.32 ; p=0.000]$ and interaction $[F(1,38)=25.53 ; p=0.000]$, but not for group $[F(1,38)=3.61 ; p=0.073]$. Post hoc Bonferroni pairwise comparisons showed that there was no significant difference between the 2 groups for $3(p=0.001)$ and $12(p=0.684)$ months after implantation.

\section{Discussion}

In recent years, some studies showed that RW insertion can reduce less intracochlear trauma than scala tympani access. Thus, the RW membrane was reconsidered as a potential site for electrode insertion [10,11,27]. Few studies have comprehensively investigated the impact on electrode impedance and functional outcomes between the RW and cochleostomy approaches for using the same type of electrode.

In the present study, the impedance was tested intraoperatively and at 1, 3 and 12 months after implantation. Our results showed that there was no significant difference in impedance between the RW and cochleostomy groups. Hamada et al. [13] showed no significant differences in electrode impedance between the RW and cochleostomy approaches for 69 pediatric and adult CI users using 4 types of electrodes 1 month after the surgery. Gu et al. [12] compared the impact of the modified minimal access CI approach which was improved basing it on RW approach and cochleostomy approaches for 50 pediatric and adult CI users using the same type of electrode and found that electrode impedance values were significantly lower in the minimal access CI group than in the cochleostomy group at initial activation. The minimal access CI group used dexamethasone before they inserted the electrode. 
Cheng et al.: Impedance and Speech after Cochlear Implantation Using Round Window versus Cochleostomy

However, some studies had shown that dexamethasone can significantly reduce tissue fibrosis, which would reduce electrode impedance [28]. Thus, the results of the study might not indicate the impact of the RW and cochleostomy approaches on electrode impedance. Some studies showed that increased impedance had a correlation with fibrous tissue growth around the electrode $[28,29]$. In this study, there was no significant difference in the impedance between the RW and cochleostomy groups using the same electrode type at 4 time points, which may indicate that different surgical techniques might have similar degrees of fibrous growth.

We compared different turns of impedance for the RW and cochleostomy groups, and the results showed that there was no significant difference for apical, middle and basal turns between the 2 groups. For the basal turn, there was a significant difference between the RW and cochleostomy groups at 0 month after implantation, which indicated that the cochleostomy approach may be more traumatic than the RW approach, thus inducing more basal turn fibrosis. However, there was no significant difference for the impedance 1, 3 and 12 months after implantation, which indicated that different surgical techniques may affect intraoperative impedance but not for long-term impedance.

Here, we also examined whether different surgical techniques would affect the patients' performance. As can be observed in Figures 3 and 4, the results of tone, vowel, consonant and disyllable perception of the RW and cochleostomy groups were consistent with the previous studies [30-32], whereas the sentence perception of those patients was not good, which may be impacted by the different test material and approach. There was a significant difference between the 2 groups 3 months after implantation for the sentence perception, whereas there was no significant difference in tone, vowel, consonant, disyllable and sentence perception of the RW and cochleostomy groups 12 months after implantation. Adunka et al. [14] compared the effects of the residual hearing and speech perception (CNC words and CUNY sentences) between 8 patients using the cochleostomy approach and 12 patients using the RW approach 12 months after surgery, and the results showed no statistically significant differences between the 2 groups in the preservation of residual hearing and speech perception. Kang and Kim [17] compared speech perception of 2 groups for cochlear implant users who used different electrodes $3,6,12,24,36$ and 48 months after implantation. They showed that the speech perception of the RW group demonstrated comparable results compared with the cochleostomy insertion group. The results indicated that the different surgical approaches may impact the short-term sentence perception, yet not for long-term sentence perception. The speech materials of this study were mainly used for evaluating the speech perception of children [26], thus the speech testing may be too easy for adult patients, which may impact the results of speech perception between those two groups. Therefore, in future work, we should further explore the difference between the groups for speech perception in noise or for music perception.

\section{Conclusion}

In summary, the results of the present study suggested that different insertion techniques of the RW and cochleostomy approaches might induce different degrees of intraoperative damage in the basal turn and the short-term sentence perception, whereas they provided a comparable impact on electrode impedance and speech perception 12 months after implantation. 
Cheng et al.: Impedance and Speech after Cochlear Implantation Using Round Window versus Cochleostomy

\section{Disclosure Statement}

This work was funded by the National Nature Science Foundation of China $(81570914,81700925$, 81771013) and Science and Technology Commission of Shanghai Municipality (17ZR1448600). The authors have no funding, financial relationships or conflicts of interest to disclose.

\section{References}

1 Parisier SC, Chute P, Parisier ES: Cochlear implant: a treatment for profound neurosensory deafness. Bull NY Acad Med 1983;59:784-789.

2 Macherey O, Carlyon RP: Cochlear implants. Curr Biol 2014;24:R878-R884.

3 Shearer AE, Eppsteiner RW, Frees K, Tejani V, Sloan-Heggen CM, Brown C, Abbas P, Dunn C, Hansen MR, Gantz BJ, Smith RJH: Genetic variants in the peripheral auditory system significantly affect adult cochlear implant performance. Hear Res 2017;348:138-142.

4 Chen Y, Wong LL, Zhu S, Xi X: Vocabulary development in Mandarin-speaking children with cochlear implants and its relationship with speech perception abilities. Res Dev Disabil 2017;60:243-255.

5 Wu CM, Ko HC, Tsou YT, Lin YH, Lin JL, Chen CK, Chen PL, Wu CC: Long-term cochlear implant outcomes in children with GJB2 and SLC26A4 mutations. PLoS One 2015;10:e0138575.

6 Farhood Z, Nguyen SA, Miller SC, Holcomb MA, Meyer TA, Rizk HG: Cochlear implantation in inner ear malformations: systematic review of speech perception outcomes and intraoperative findings. Otolaryngol Head Neck Surg 2017;156:783-793.

7 Muller J, Brill S, Hagen R, Moeltner A, Brockmeier SJ, Stark T, Helbig S, Maurer J, Zahnert T, Zierhofer C, Nopp $\mathrm{P}$, Anderson I: Clinical trial results with the MED-EL fine structure processing coding strategy in experienced cochlear implant users. ORL J Otorhinolaryngol Relat Spec 2012;74:185-198.

8 Ruff S, Bocklet T, Noth E, Muller J, Hoster E, Schuster M: Speech production quality of cochlear implant users with respect to duration and onset of hearing loss. ORL J Otorhinolaryngol Relat Spec 2017;79:282-294.

9 Chen Z, Yu D, Wu Y, Zhou H, Shi H, Yin S: Indications and common surgical approaches for cochlear implantation in China. ORL J Otorhinolaryngol Relat Spec 2009;71:187-191.

10 Adunka O, Unkelbach MH, Mack M, Hambek M, Gstoettner W, Kiefer J: Cochlear implantation via the round window membrane minimizes trauma to cochlear structures: a histologically controlled insertion study. Acta Otolaryngol 2004;124:807-812.

11 Roland PS, Wright CG, Isaacson B: Cochlear implant electrode insertion: the round window revisited. Laryngoscope 2007;117:1397-1402.

12 Gu P, Jiang Y, Gao X, Huang S, Yuan Y, Wang G, Li B, Xi X, Dai P: Effects of cochlear implant surgical technique on post-operative electrode impedance. Acta Otolaryngol 2016;136:677-681.

13 Hamada S, Omara A, Sefein I, Younes A: The impact of electrode type on intraoperative and postoperative telemetry measures in cochlear implant using different surgical technique. Egypt J Otolaryngol 2016;32:264.

14 Adunka OF, Dillon MT, Adunka MC, King ER, Pillsbury HC, Buchman CA: Cochleostomy versus round window insertions: influence on functional outcomes in electric-acoustic stimulation of the auditory system. Otol Neurotol 2014;35:613-618.

15 Sun $\mathrm{CH}, \mathrm{Hsu}$ CJ, Chen PR, Wu HP: Residual hearing preservation after cochlear implantation via round window or cochleostomy approach. Laryngoscope 2015;125:1715-1719.

16 Hassepass F, Aschendorff A, Bulla S, Arndt S, Maier W, Laszig R, Beck R: Radiologic results and hearing preservation with a straight narrow electrode via round window versus cochleostomy approach at initial activation. Otol Neurotol 2015;36:993-1000.

17 Kang BJ, Kim AH: Comparison of cochlear implant performance after round window electrode insertion compared with traditional cochleostomy. Otolaryngol Head Neck Surg 2013;148:822-826.

18 Hod R, Attias J, Raveh E, Nageris BI: Cochlear implantation via round window or cochleostomy: effect on hearing in an animal model. Laryngoscope 2016;126:E375-E378.

19 Rowe D, Chambers S, Hampson A, Eastwood H, Campbell L, O'Leary S: Delayed low frequency hearing loss caused by cochlear implantation interventions via the round window but not cochleostomy. Hear Res 2016; 333:49-57.

20 Newbold C, Mergen S, Richardson R, Seligman P, Millard R, Cowan R, Shepherd R: Impedance changes in chronically implanted and stimulated cochlear implant electrodes. Cochlear Implants Int 2014;15:191-199.

21 Paasche G, Bockel F, Tasche C, Lesinski-Schiedat A, Lenarz T: Changes of postoperative impedances in cochlear implant patients: the short-term effects of modified electrode surfaces and intracochlear corticosteroids. Otol Neurotol 2006;27:639-647.

22 Zhu M, Fu QJ, Galvin JJ 3rd, Jiang Y, Xu J, Xu C, Tao D, Chen B: Mandarin Chinese speech recognition by pediatric cochlear implant users. Int J Pediatr Otorhinolaryngol 2011;75:793-800.

23 Kirk KI, Sehgal M, Miyamoto RT: Speech perception performance of nucleus multichannel cochlear implant users with partial electrode insertions. Ear Hear 1997;18:456-471. 
Cheng et al.: Impedance and Speech after Cochlear Implantation Using Round Window versus Cochleostomy

24 Marx M, James C, Foxton J, Capber A, Fraysse B, Barone P, Deguine O: Speech prosody perception in cochlear implant users with and without residual hearing. Ear Hear 2015;36:239-248.

25 Jiam NT, Jiradejvong P, Pearl MS, Limb CJ: The effect of round window vs cochleostomy surgical approaches on cochlear implant electrode position: a flat-panel computed tomography study. JAMA Otolaryngol Head Neck Surg 2016;142:873-880.

26 Sun XB, Zhang F, Huang HY, et al: Speech hearing assessment method for hearing impaired children (in Chinese). J Aud Speech Dis 2009;17:327-329.

27 Richard C, Fayad JN, Doherty J, Linthicum FH Jr: Round window versus cochleostomy technique in cochlear implantation: histologic findings. Otol Neurotol 2012;33:1181-1187.

28 Wilk M, Hessler R, Mugridge K, Jolly C, Fehr M, Lenarz T, Scheper V: Impedance changes and fibrous tissue growth after cochlear implantation are correlated and can be reduced using a dexamethasone eluting electrode. PLoS One 2016;11:e0147552.

29 Huang CQ, Tykocinski M, Stathopoulos D, Cowan R: Effects of steroids and lubricants on electrical impedance and tissue response following cochlear implantation. Cochlear Implants Int 2007;8:123-147.

30 Chen Y, Wong LL, Chen F, Xi X: Tone and sentence perception in young Mandarin-speaking children with cochlear implants. Int J Pediatr Otorhinolaryngol 2014;78:1923-1930.

31 Zhu M, Wang X, Fu QJ: Development and validation of the Mandarin disyllable recognition test. Acta Otolaryngol 2012;132:855-861.

32 Chang YP, Chang RY, Lin CY, Luo X: Mandarin tone and vowel recognition in cochlear implant users: effects of talker variability and bimodal hearing. Ear Hear 2016;37:271-281. 